\title{
A Girl with Autoimmune Cytopenias, Nonmalignant Lymphadenopathy, and Recurrent Infections
}

\author{
Marjolein A. C. Mattheij, ${ }^{1,2}$ Ellen J. H. Schatorjé,, ${ }^{1,3}$ Eugenie F. A. Gemen, ${ }^{4}$ \\ Lisette van de Corput, ${ }^{5}$ Peet T. G. A. Nooijen, ${ }^{6}$ Mirjam van der Burg, ${ }^{7}$ and Esther de Vries ${ }^{1}$ \\ ${ }^{1}$ Department of Pediatrics, Jeroen Bosch Hospital, P.O. Box 90153, 5200 ME 's-Hertogenbosch, The Netherlands \\ ${ }^{2}$ University Medical Centre Antwerp, Antwerp, Belgium \\ ${ }^{3}$ Radboud University Medical Centre Nijmegen, Nijmegen, The Netherlands \\ ${ }^{4}$ Laboratory for Clinical Chemistry and Hematology, Jeroen Bosch Hospital, P.O. Box 90153, \\ 5200 ME's-Hertogenbosch, The Netherlands \\ ${ }^{5}$ Department of Medical Immunology, University Medical Center Utrecht, P.O. Box 85500, Utrecht, The Netherlands \\ ${ }^{6}$ Department of Pathology, Jeroen Bosch Hospital, P.O. Box 90153, 5200 ME 's-Hertogenbosch, The Netherlands \\ ${ }^{7}$ Department of Immunology, Erasmus Medical Center, P.O. Box 2040, 3000 CA Rotterdam, The Netherlands \\ Correspondence should be addressed to Esther de Vries, e.d.vries@jbz.nl
}

Received 28 August 2012; Accepted 9 October 2012

Academic Editors: V. Lougaris and A. Plebani

Copyright ( 2012 Marjolein A. C. Mattheij et al. This is an open access article distributed under the Creative Commons Attribution License, which permits unrestricted use, distribution, and reproduction in any medium, provided the original work is properly cited.

We describe a girl, now 9 years of age, with chronic idiopathic thrombocytopenic purpura, persistent nonmalignant lymphadenopathy, splenomegaly, recurrent infections, and autoimmune hemolytic anemia. Her symptoms partly fit the definitions of both autoimmune lymphoproliferative syndrome (ALPS) and common variable immunodeficiency disorders (CVIDs). Genetic analysis showed no abnormalities in the ALPS-genes FAS, FASLG, and CASP10. The CVID-associated TACI gene showed a homozygous polymorphism (Pro251Leu), which is found also in healthy controls.

\section{Introduction}

Acute idiopathic thrombocytopenic purpura (ITP) is a wellknown clinical entity in children. Generally, in children the disease is self-limiting and easily distinguished from a hematological malignancy, even without investigating the bone marrow [1]. However, the case becomes more complicated when the ITP becomes chronic and accompanying profound lymphadenopathy develops. We describe the diagnostic dilemma in a girl with these problems, who with time also developed recurrent respiratory infections, suffered from a prolonged episode of intractable diarrhea, a severe episode of varicella zoster infection and autoimmune hemolytic anemia.

\section{Patient}

The girl, now 9 years of age, is the second child of healthy nonconsanguineous Caucasian parents. She was born after an uncomplicated pregnancy and delivery and showed normal growth and development. Her family history reveals allergy on the paternal side and autoimmune disease and malignancies on the maternal side. At the age of 14 months, she developed ITP and showed a partial slow recovery after 3 days of high-dose intravenous immunoglobulins (IVIGs) followed by prednisolone. One year later, she suffered a relapse during a mild parainfluenza type 3 infection and treatment with 3 days of high-dose IVIG was started again. A few days after receiving this second course of high-dose IVIG she developed cervical, axillary and inguinal lymphadenopathy and enlarged tonsils: this lymphadenopathy never resolved. There was no hepatomegaly, splenomegaly, or mediastinal or abdominal lymph node enlargement at that time. Blood tests showed a mild normocytic anemia $(\mathrm{Hb} 6.4 \mathrm{mmol} / \mathrm{L}$, MCV $77 \mathrm{fL})$ and granulocytopenia $\left(0.7-1.0 \times 10^{9} / \mathrm{L}\right)$ and large unstained cells in the hematology analyzer $(8 \%$; $0.4 \times$ $10^{9} / \mathrm{L}$ ). A bone marrow aspirate and biopsy showed some atypical lymphocytes and specific maturational disturbances, 
but no malignancy. Bone marrow immunophenotyping was normal. FAS-mediated apoptosis of T-lymphoblasts was normal (two separate tests in two different laboratories). She suffered from recurrent upper respiratory tract infections and two pneumonias in the following years and a prolonged episode of intractable diarrhea. The infection frequency improved on cotrimoxazole prophylaxis. The enlarged tonsils, cervical, axillary and inguinal lymphadenopathy and variable amounts of atypical lymphocytes in her differential remained, splenomegaly developed as well. The parents increasingly felt that she got tired more easily than other children of her age. At the age of 5 years, an adenoidectomy was performed; this procedure was combined with an excision of an inguinal lymph node for histological examination. At the age of 7 years, an episode of severe varicella zoster infection occurred which was treated successfully with 1 week of intravenous aciclovir. Five months later, she acutely developed autoimmune hemolytic anemia, which initially responded well to another course of high-dose IVIG and prednisone, but she relapsed when the prednisone was slowly tapered and stopped. Unexpectedly, her chronic thrombocytopenia improved upon this treatment. At the age of 8 years, she developed pulmonary problems with dyspnea after an (probably viral) airway infection; high resolution CT scan showed a granulomatous lymphocytic interstitial lung disease (GLILD), a form of pulmonary lymphoproliferative disease. Therapy with mycophenolic acid was started, after which she showed a slow but nearly complete pulmonary recovery; she is still slightly dyspneic upon exertion. She also developed a uveitis, which was treated with prednisolone eye drops. Now, at the age of 9 years, she is relatively stable on mycophenolic acid; stem cell transplantation is being considered.

\section{Material and Methods}

Upon her first presentation at the pediatric immunology clinic in 's-Hertogenbosch at 5 years of age, extensive investigations were performed (Table 1). Four-color immunophenotyping was performed as previously described [2, 3]. One representative paraffin-embedded tissue block of both lymph node $(18 \mathrm{~mm})$ and adenoid $(20 \mathrm{~mm})$ was selected and immunohistochemical stainings were performed (Table 2). Routine protocols for Benchmark XT Ventana were used. Kappa, lambda, and EBV were assessed using routine in situ hybridisation technique (Kappa, ISH, Ventana; lambda, ISH, Ventana; EBER). Genomic DNA was isolated from peripheral blood granulocytes using the autopure kit (Qiagen, Venlo, the Netherlands). Exon-specific M13-tagged primers were used for amplification by PCR of all coding exons including flanking regions from the genes FAS (NCBI NM_00043), FASLG (NCBI NM_000639), CASP10 (NCBI NM_032974) and TACI (TNFRSF13B, NCBI NM_012452) followed by fluorescent sequencing (Applied Biosystems BigDye Terminator v1.1 Applied Biosystems).

\section{Results}

Table 1 shows the lymphocyte subpopulations in comparison with age-matched reference values from our laboratory [2].
T-lymphocytes were slightly low to just normal, naive helperT-lymphocytes and recent thymic emigrants were clearly decreased; double-negative TCR $\alpha \beta^{+}$T-lymphocytes (cells without expression of CD4 or CD8 coreceptors) were normal to just increased in subsequent experiments, performed during episodes without immunosuppressive treatment.

Histological examination of lymphoid tissue revealed retention of the architectural features with a combined mild follicular hyperplasia and mild paracortical T zone expansion. In one lymph node a single granuloma was observed without necrosis or eosinophilia. Ziehl-Neelsen and other stainings for microorganisms were negative. The CD20 and CD79 positive B-cells were restricted to the normal Bcell areas. The follicular centres were highlighted by CD21 and CD23 B-cells, which stained the follicular dendritic cell meshwork. T-lymphocytes $\left(\mathrm{CD} 2^{+}, \mathrm{CD}^{+}\right)$showed mild expansion in the paracortical $\mathrm{T}$ zone. BCL2 was negative and the proliferation in MIB1 was mainly restricted to the centrocytes and centroblasts in the reactive follicular centres. Kappa and lambda revealed a polyclonal plasma cell population. ALK staining was negative, there was no pathological CD30 staining. There were no signs of Rosai Dorfman; EBV was negative. Thus, histological examination showed abnormalities, but did not point to a specific diagnosis.

Analysis of the FAS, FASLG, and CASP10 genes revealed no abnormalities. Direct fluorescent sequencing of the TACI gene showed two polymorphisms, a homozygote polymorphism (p.Pro251Leu), and a heterozygote silent polymorphism.

\section{Discussion}

The girl we describe poses a diagnostic dilemma: there are several clinical entities that can be considered. Firstly, she undoubtedly fits the diagnosis of "Evans syndrome"which is defined by the presence of at least two autoimmune cytopenias - since she suffers from chronic idiopathic thrombocytopenic purpura and autoimmune hemolytic anemia [4]. However, this is only a descriptive diagnosis that does not encompass all her features. "Evans syndrome" is increasingly being associated with specific diseases, such as autoimmune lymphoproliferative syndrome (ALPS) and common variable immunodeficiency (CVID) and, mainly in adults, lymphoproliferative disorders [4-8].

Since she also suffers from persistent nonmalignant lymphadenopathy and splenomegaly, ALPS is an option for this girl. ALPS is a disorder of lymphocyte apoptosis leading to chronic nonmalignant lymphoproliferation. Affected individuals often suffer from autoimmune cytopenia, splenomegaly and hepatomegaly [9]. Laboratory findings include hypergammaglobulinemia and expansion of a unique population of circulating T-lymphocytes, referred to as TCR $\alpha \beta^{+}$double negative T-cells which owe their name to the fact that they do not express CD4 or CD8 coreceptors [10]. These T-cells respond poorly to antigens. The genetic deficit in most patients is a mutation in the FAS gene which encodes a cell surface receptor which, upon stimulation, induces programmed cell death [11]. The diagnostic criteria for ALPS have recently been revised. The two required 
TABLE 1: Investigations in peripheral blood.

\begin{tabular}{|c|c|c|}
\hline General investigations & Results & Interpretation \\
\hline Hemoglobin & $7.5-7.9 \mathrm{mmol} / \mathrm{L}$ & Low to normal \\
\hline Neutrophils & $1.3-5.3 \times 10^{9} / \mathrm{L}$ & Intermittently low \\
\hline Lymphocytes & $1.6-3.2 \times 10^{9} / \mathrm{L}$ & Low \\
\hline $\mathrm{ACE}$ & $73 \mathrm{U} / \mathrm{mL}$ & Mildly elevated \\
\hline ANCA & Negative & Normal \\
\hline ANA & Negative & Normal \\
\hline TPO-antibodies & Negative & Normal \\
\hline Thyreoglobulin antibodies & Negative & Normal \\
\hline Serology rubella & IgG pos, IgM neg & Normal after vaccination \\
\hline Serology CMV & IgG and IgM neg & No exposure \\
\hline Serology EBV & IgG and IgM neg & No exposure \\
\hline Serology HIV & Negative & No exposure \\
\hline Serology parvovirus & IgG and IgM neg & No exposure \\
\hline Serology bartonella henselae & IgM negative & No recent exposure \\
\hline Serology toxoplasma gondii & IgG and IgM neg & No exposure \\
\hline PCR blood CMV & Negative & No recent exposure \\
\hline PCR blood EBV & Negative & No recent exposure \\
\hline Antibody response to diphtheria and tetanus toxoid antigens & $>4$-fold increase in titer & Normal \\
\hline Antibody response to pneumococcal polysaccharides & 2 -fold increase in titer & Weak response \\
\hline Mantoux & Negative & Normal \\
\hline M-proteins & Negative & Normal \\
\hline IgM (age 7 years) & $1.03 \mathrm{~g} / \mathrm{L}$ & Normal \\
\hline IgA (age 7 years) & $0.19 \mathrm{~g} / \mathrm{L}$ & Low \\
\hline IgG (age 7 years) & $13.4 \mathrm{~g} / \mathrm{L}$ & Mildly elevated \\
\hline IgG1 (age 7 years) & $11.6 \mathrm{~g} / \mathrm{L}$ & Mildly elevated \\
\hline IgG2 (age 7 years) & $0.92 \mathrm{~g} / \mathrm{L}$ & Normal \\
\hline IgG3 (age 7 years) & $1.55 \mathrm{~g} / \mathrm{L}$ & Mildly elevated \\
\hline IgG4 (age 7 years) & 0.058 & Normal \\
\hline Blood lymphocyte subpopulations & Absolute count* & Age-matched reference ${ }^{* *}$ \\
\hline Leucocytes & 4.6 & $9.3(4.5-14)$ \\
\hline Lymphocytes & 1.94 & $2.4(1.2-4.7)$ \\
\hline T-lymphocytes $(\mathrm{T})\left(\mathrm{CD}^{+}\right)$ & 1.01 & $1.80(0.77-4.0)$ \\
\hline Double negative TCR $\alpha \beta^{+} \mathrm{T}\left(\mathrm{CD} 3^{+} \mathrm{TCR} \alpha \beta^{+} \mathrm{CD} 4^{-} \mathrm{CD} 8^{-}\right)$ & 0.08 & $0.03(0.01-0.1)$ \\
\hline Helper-T-lymphocytes $(\mathrm{Th})\left(\mathrm{CD} 3^{+} \mathrm{CD} 4^{+}\right)$ & 0.58 & $0.91(0.36-2.80)$ \\
\hline Th naive $\left(\mathrm{CD}^{+}{ }^{+} \mathrm{CD} 4^{+} \mathrm{CD} 45 \mathrm{RA}^{+} \mathrm{CD} 27^{+}\right)$ & 0.11 & $0.70(0.20-2.50)$ \\
\hline Th terminally differentiated $\left(\mathrm{CD} 3^{+} \mathrm{CD} 4^{+} \mathrm{CD} 45 \mathrm{RA}^{+} \mathrm{CD} 27^{-}\right)$ & 0 & $0.00(0.00-0.03)$ \\
\hline Th central memory $\left(\mathrm{CD} 3^{+} \mathrm{CD} 4^{+} \mathrm{CD} 45 \mathrm{RA}^{-} \mathrm{CD} 27^{+}\right)$ & 0.45 & $0.18(0.00-0.51)$ \\
\hline Th effector memory $\left(\mathrm{CD}^{+}{ }^{+} \mathrm{CD} 4^{+} \mathrm{CD} 45 \mathrm{RA}^{-} \mathrm{CD} 27^{-}\right)$ & 0.02 & $0.02(0.00-0.17)$ \\
\hline Cytotoxic T-lymphocytes (Tc) $\left(\mathrm{CD} 3^{+} \mathrm{CD}^{+}\right)$ & 0.19 & $0.60(0.20-1.70)$ \\
\hline Tc naive $\left(\mathrm{CD} 8^{+} \mathrm{CD} 45 \mathrm{RA}^{+} \mathrm{CD} 197^{+} \mathrm{CD} 27^{+}\right)$ & 0.09 & $0.24(0.04-1.30)$ \\
\hline 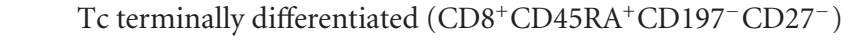 & $\mathbf{0}$ & $0.14(0.06-0.34)$ \\
\hline Tc central memory $\left(\mathrm{CD} 8^{+} \mathrm{CD} 45 \mathrm{RA}^{-} \mathrm{CD} 197^{+} \mathrm{CD} 27^{+}\right)$ & 0.08 & $0.02(0.01-0.04)$ \\
\hline Tc effector memory $\left(\mathrm{CD} 8^{+} \mathrm{CD}^{2} 5 \mathrm{RA}^{-} \mathrm{CD} 197^{-} \mathrm{CD} 27^{-}\right)$ & 0.2 & $0.14(0.05-0.41)$ \\
\hline Recent thymic emigrants $\left(\mathrm{CD} 3^{+} \mathrm{CD} 4^{+} \mathrm{CD} 45 \mathrm{RA}^{+} \mathrm{CD} 31^{+}\right)$ & 0.1 & $0.59(0.20-1.70)$ \\
\hline Regulatory T $\left(\mathrm{CD} 3^{+} \mathrm{CD} 4^{+} \mathrm{CD} 25^{++} \mathrm{CD} 127^{-}\right)$ & $\mathbf{0}$ & $0.07(0.02-0.27)$ \\
\hline B-lymphocytes (B) $\left(\mathrm{CD} 19^{+}\right)$ & 0.45 & $0.29(0.10-0.80)$ \\
\hline Naive B $\left(\mathrm{CD} 19^{+} \mathrm{CD} 27^{-} \operatorname{IgM}^{+} \operatorname{IgD}^{+}\right)$ & 0.37 & $0.21(0.07-0.63)$ \\
\hline Natural effector B $\left(\mathrm{CD} 19^{+} \mathrm{CD} 27^{+} \operatorname{IgM}^{+} \operatorname{IgD}^{+}\right)$ & 0.06 & $0.03(0.01-0.09)$ \\
\hline Switched memory B $\left(\mathrm{CD} 19^{+} \mathrm{CD} 27^{+} \operatorname{IgM}^{-} \operatorname{IgD}^{-}\right)$ & 0.01 & $0.02(0.01-0.05)$ \\
\hline Transitional B $\left(\mathrm{CD} 19^{+} \mathrm{CD} 38^{++} \operatorname{IgM}^{++}\right)$ & 0.01 & $0.03(0.01-0.07)$ \\
\hline
\end{tabular}


TABle 1: Continued.

\begin{tabular}{lcc}
\hline Blood lymphocyte subpopulations & Absolute count* & Age-matched reference $^{* *}$ \\
\hline \multicolumn{1}{c}{$\mathrm{CD}^{+} \mathrm{B}\left(\mathrm{CD} 19^{+} \mathrm{CD}^{+}\right)$} & 0.11 & $0.09(0.02-0.46)$ \\
$\mathrm{CD} 10^{+} \mathrm{B}\left(\mathrm{CD} 19^{+} \mathrm{CD} 10^{+}\right)$ & 0.08 & $0.05(0.01-0.21)$ \\
\hline NK-cells $\left(\mathrm{CD} 3^{-} / \mathrm{CD} 16\right.$ and/or $56^{+}$cells $)$ & 0.14 & $0.20(0.07-0.59)$ \\
\hline & Ratio & Age-matched reference \\
\hline TCR- $\alpha \beta /$ TCR- $\gamma \delta$ & 32.7 & 9.4 \\
Th/Tc & 3.1 & 1.7 \\
$\kappa / \lambda$ & 1.14 & 1.5 \\
\hline & Percentage & Reference \\
\hline TACI ${ }^{+}$cells & 10.6 & $2.6(1-12.6)^{* * *}$ \\
BAFF- $^{+}$cells & 99.5 & $>95^{* * * *}$ \\
\hline
\end{tabular}

All investigations were performed at the age of 5 years, unless otherwise stated. ACE: angiotensin converting enzyme; ANCA: antineutrophil cytoplasmic antibody; ANA: antinuclear antibody; BAFF: B-cell activating factor; CMV: cytomegalovirus; EBV: epstein-barr virus; HIV: human immunodeficiency virus; Ig: immunoglobulin; neg: negative; NK: Natural Killer; R: receptor; pos: positive; SD: standard deviation; TACI: transmembrane activator and calciummodulator and cyclophilin ligand interactor; Tc: T-cytotoxic; TCR: T-cell receptor; Th: T-helper; TPO-antibodies: thyroid peroxidase antibody. $* 10^{9} / \mathrm{L}$, values in bold represent values that fall outside of the normal range. ${ }^{* *}$ Mean, $90 \%$ range. ${ }^{* * *}$ Mean; total range. ${ }^{* * * *}$ Total range. For T-lymphocyte reference values see [3], for B-lymphocyte reference values see [2].

TABLE 2: Used antibodies.

\begin{tabular}{|c|c|}
\hline Antibody & Source* \\
\hline \multicolumn{2}{|l|}{ Determination of blood lymphocyte subpopulations } \\
\hline \multicolumn{2}{|l|}{ CD3, CD4, CD5, CD8, CD10, CD14, CD16, CD19, CD20, CD21, CD24, } \\
\hline CD25, CD27, CD31, CD38, CD45, CD45RA, CD45RO, CD56, CD127, & Becton Dickinson \\
\hline \multicolumn{2}{|l|}{ CD197, CD268, TCR $\alpha \beta, \operatorname{TCR} \gamma \delta$, cylgG1 } \\
\hline CD185 & Research and Diagnostics Systems \\
\hline cyCD257 & eBioscience \\
\hline CD267 (biotin) & PeproTech \\
\hline IgD, IgM, Kappa, Lambda & Dakopatts \\
\hline \multicolumn{2}{|l|}{ Immunohistochemical investigations } \\
\hline CD2 (AB75, 1:200), CD4 (1H6), CD8 (C8/144B, 1:50), CD23 (1B12), & Monosan \\
\hline \multicolumn{2}{|l|}{ CD56 (123C3.D5), BCL2 (124) } \\
\hline \multicolumn{2}{|l|}{ CD3 (polyclonal), CD5 (4C7), CD10 (56C6), CD15 (MMA), CD21 (2G9), } \\
\hline CD30 (BER-H2), & Ventana \\
\hline \multicolumn{2}{|l|}{ CD45 (RP2/18), CD79a (JCB117), ALK (ALK-01), Mib-1 (30-9) } \\
\hline CD20 (L26,1:400) & Dakopatts \\
\hline
\end{tabular}

*Becton Dickinson Biosciences (California, CA, USA), Research and Diagnostics Systems (Minneapolis, MN, USA), eBioscience (San Diego, CA, USA), PeproTech (Rocky Hill, CT, USA), Dakopatts (Glostrup, Denmark), Monosan (Uden, The Netherlands), and Ventana (Tucson, AZ, USA).

criteria for the diagnosis of ALPS are (1) chronic ( $>6$ months), nonmalignant, noninfectious, lymphadenopathy, or/and splenomegaly, (2) elevated $\mathrm{CD} 3^{+} \mathrm{TCR} \alpha \beta^{+} \mathrm{CD} 4^{-} \mathrm{CD} 8^{-}$ double-negative T-cells [10]. There are also four secondary accessory criteria; for a definite ALPS diagnosis a patient has to meet both required criteria and one of the primary accessory criteria. The diagnosis of ALPS is probable when two required criteria and any one of the secondary accessory criteria is present [10]. According to these criteria, our patient does not have ALPS, since she does not have consistently elevated $\mathrm{CD} 3^{+} \mathrm{TCR} \alpha \beta^{+} \mathrm{CD} 4^{-} \mathrm{CD} 8^{-}$double-negative T-cells. There are several well-defined ALPS-related disorders. Of these, RALD (RAS-associated autoimmune lymphoprolipherative disease) could be an option, but our girl shows no characteristic features of this disorder such as elevations in cells of myeloid origin [10].
The girl's recurrent infections could point to possible CVID. This disease is characterized by recurrent infections and hypogammaglobulinemia. Additional clinical manifestations vary, but can include autoimmunity, splenomegaly and nonmalignant lymphoproliferation [9]. CVID is a heterogeneous group of disorders; the age of onset can be in childhood, adolescence, or even adult life. Most patients have no molecular diagnosis as yet; cases can be sporadic, or familial. There is a high incidence of hematological malignancies in CVID [12]. For a definite diagnosis, all of the following criteria need to be present: (1) onset of immunodeficiency at greater than 2-4 years of age, (2) absent isohemagglutinins and/or poor response to vaccines and (3) exclusion of defined causes of hypogammaglobulinemia. Criteria for the diagnosis of probable CVID are a marked decrease of IgG (at least 2 SD below the mean for age) and 
TABLE 3: Signs of ALPS and CVID definitions in our patient.

\begin{tabular}{|c|c|}
\hline ALPS $^{10}$ & \\
\hline \multicolumn{2}{|l|}{ Required criteria: } \\
\hline Chronic nonmalignant noninfectious lymphoproliferation & + \\
\hline Elevated $\mathrm{CD} 3^{+} \mathrm{TCR} \alpha \beta^{+} \mathrm{CD} 4^{-} \mathrm{CD} 8^{-}$double-negative T-cells & \pm \\
\hline \multicolumn{2}{|l|}{ Accessory criteria: } \\
\hline \multicolumn{2}{|l|}{ Primary: } \\
\hline Pathogenic mutation in FAS, FASLG, or CASP10 genes & - \\
\hline Defective lymphocyte apoptosis (in 2 separate assays) & - \\
\hline \multicolumn{2}{|l|}{ Secondary: } \\
\hline $\begin{array}{l}\text { Elevated soluble FASL or serum interleukin-10 or interleukin-18 or serum } \\
\text { plasma vit B12 levels }\end{array}$ & \# \\
\hline Typical immunohistological findings & - \\
\hline Autoimmune cytopenias and elevated IgG levels & + \\
\hline Family history of nonmalignant noninfectious lymphoproliferation & - \\
\hline \multicolumn{2}{|l|}{ CVID } \\
\hline Hypogammaglobulinemia & $\pm($ IgA deficiency $)$ \\
\hline Specific antibody deficiency & $\pm($ antipolysaccharide response decreased $)$ \\
\hline Autoantibodies & - \\
\hline Malignancy & - \\
\hline Lymphadenopathy & + \\
\hline Splenomegaly & + \\
\hline
\end{tabular}

a marked decrease in at least one of the isotypes IgM or IgA and for possible CVID a marked decrease (at least 2 SD below the mean for age) in one of the major isotypes (IgM, IgG, and IgA) [11]. Our patient, however, only suffers from IgA deficiency and shows reasonable responses to vaccines.

The girl, therefore, only partly fits ALPS as well as CVID definitions (Table 3 ) and the diagnosis remains obscure. Even extensive genetic analysis did not help in this case. The ALPSgenes FAS, FASLG and CASP10 revealed no abnormalities; the CVID-associated TACI-gene showed one homozygous polymorphism (Pro251Leu). This homozygous polymorphism has been identified in 6 out of 912 healthy controls from Sweden, similar to what is seen in CVID or IgAdeficient patients (Personal communication U. Salzer, Centre of Chronic Immunodeficiency, University Medical Centre, Freiburg, Germany). Moreover, recent work showed that the terminal intracellular part of TACI including Pro251Leu is dispensable for TACI signaling, which also supports the view that the Pro251Leu variation is not harmful [13].

Now and then, pediatric hematologists and immunologists are confronted with a patient like this without a clear diagnosis where manifestations overlap between these two adjacent fields and the clinical course is different from what is usually seen. As also shown by this girl, not all cases of autoimmune thrombocytopenia in children are self-limiting, nor all persistent profound lymphadenopathies malignant. These "hematological" features can be the first manifestation of a primary immunodeficiency syndrome. Unfortunately, this girl also illustrates that despite recent successes in further classifying primary immunodeficiencies, there are still children with clinical and laboratory features which linger between several diagnostic entities. It is important to share the medical history of these children with other specialists in the field, so that combination of experience may enhance further classification of these diseases in the future.

\section{Authors' Contribution}

All the authors meet the following conditions: (1) substantial contributions to conception and design, acquisition of data, or analysis and interpretation of data; (2) drafting the paper or revising it critically for important intellectual content; (3) final approval of the version to be published. E. J. H. Schatorje provided the information about agematched reference values for the lymphocytes; E. F. A. Gemen provided the information about the material and methods for the lymphocyte subpopulations and interpretation of these data; L. van de Corput provided information about the material and methods for the FAS, FASLG, and CASP10 mutations; P. T. G. A. Nooijen provided the information about the material and methods for the lymphoid tissue and the interpretation of these data; M. van der Burg provided the information about the material and methods for the genetic analysis and the interpretation of these data. M. A. C. Mattheij is the clinical researcher and E. de Vries is the overall supervisor of this paper. 


\section{Conflict of Interests}

The authors declare that they have no conflict of interests.

\section{References}

[1] V. Blanchette and P. Bolton-Maggs, "Childhood immune thrombocytopenic purpura: diagnosis and management," Hematology/Oncology Clinics of North America, vol. 24, no. 1, pp. 249-273, 2010.

[2] E. J. H. Schatorjé, E. F. A. Gemen, G. A. Driessen et al., "Age matched reference values for B-lymphocyte subpopulations and CVID classifications in children," Scandinavian Journal of Immunology, vol. 74, no. 5, pp. 502-510, 2011.

[3] E. J. H. Schatorjé, E. F. A. Gemen, G. A. Driessen et al., "Paediatric reference values for peripheral T cell compartment," Scandinavian Journal of Immunology, vol. 75, no. 4, pp. 436444, 2012.

[4] M. Michel, V. Chanet, A. Dechartres et al., "The spectrum of Evans syndrome in adults: new insight into the disease based on the analysis of 68 cases," Blood, vol. 114, no. 15, pp. 31673172, 2009.

[5] D. T. Teachey, "New advances in the diagnosis and treatment of autoimmune lymphoproliferative syndrome," Current Opinion in Pediatrics, vol. 24, no. 1, pp. 1-8, 2012.

[6] A. E. Seif, C. S. Manno, C. Sheen, S. A. Grupp, and D. T. Teachey, "Identifying autoimmune lymphoproliferative syndrome in children with Evans syndrome: a multi-institutional study," Blood, vol. 115, no. 11, pp. 2142-2145, 2010.

[7] A. Ramyar, A. Aghamohammadi, K. Moazzami et al., "Presence of idiopathic thrombocytopenic purpura and autoimmune hemolytic anemia in the patients with common variable immunodeficiency," Iranian Journal of Allergy, Asthma and Immunology, vol. 7, no. 3, pp. 169-175, 2008.

[8] D. T. Teachey, C. S. Manno, K. M. Axsom et al., "Unmasking Evans syndrome: T-cell phenotype and apoptotic response reveal autoimmune lymphoproliferative syndrome (ALPS)," Blood, vol. 105, no. 6, pp. 2443-2448, 2005.

[9] G. Bussone and L. Mouthon, "Autoimmune manifestations in primary immune deficiencies," Autoimmunity Reviews, vol. 8, no. 4, pp. 332-336, 2009.

[10] J. B. Oliveira, J. J. Bleesing, U. Dianzani et al., "Revised diagnostic criteria and classification for the autoimmune lymphoproliferative syndrome (ALPS): report from the 2009 NIH International Workshop," Blood, vol. 116, no. 14, pp. e35e40, 2010.

[11] J. Mohammadi, C. Liu, A. Aghamohammadi et al., "Novel mutations in TACI (TNFRSF13B) causing common variable immunodeficiency," Journal of Clinical Immunology, vol. 29, no. 6, pp. 777-785, 2009.

[12] M. B. Narra and N. I. Abdou, "Autoimmune lymphoproliferative syndrome in a patient with common variable immunodeficiency: dichotomy of apoptosis," Annals of Allergy, Asthma and Immunology, vol. 98, no. 6, pp. 585-588, 2007.

[13] B. He, R. Santamaria, W. Xu et al., "The transmembrane activator TACI triggers immunoglobulin class switching by activating B cells through the adaptor MyD88," Nature Immunology, vol. 11, no. 9, pp. 836-845, 2010. 


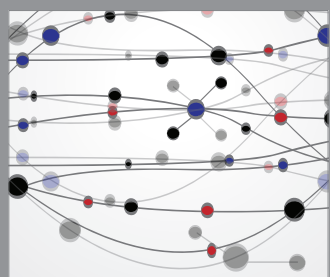

The Scientific World Journal
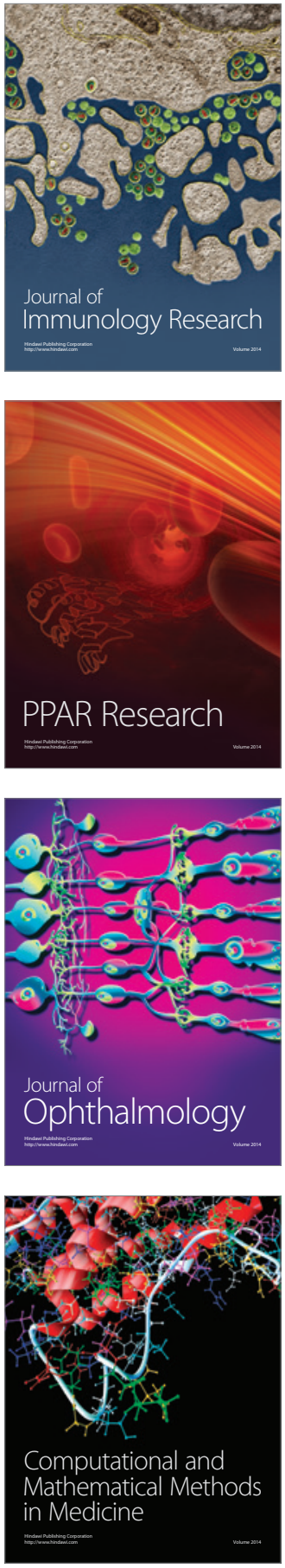

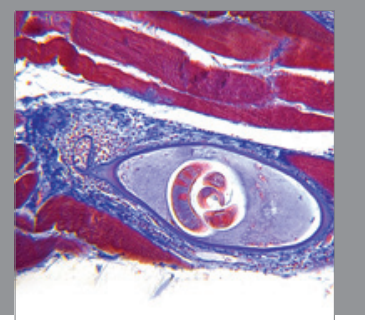

Gastroenterology

Research and Practice
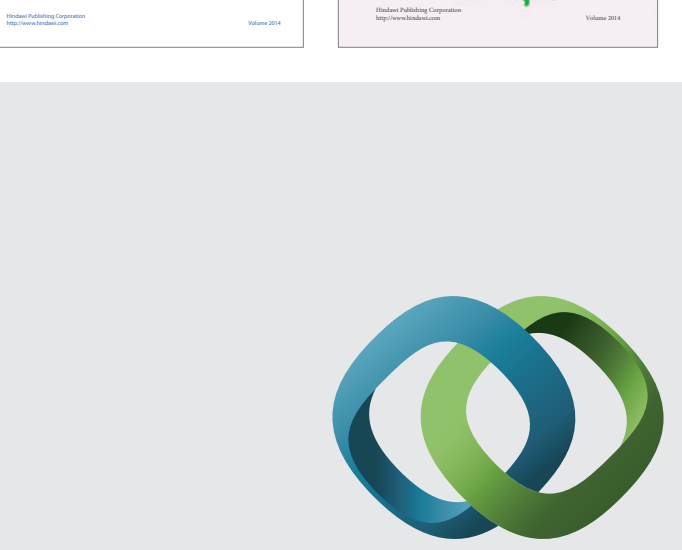

\section{Hindawi}

Submit your manuscripts at

http://www.hindawi.com
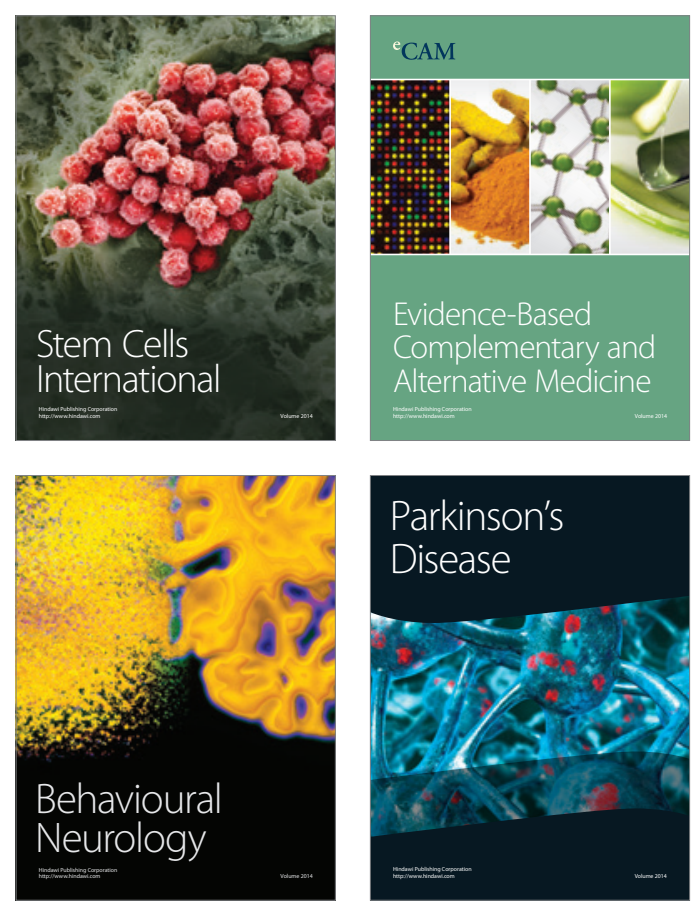

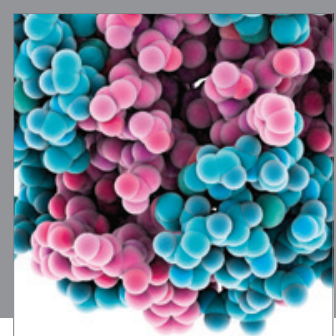

Journal of
Diabetes Research

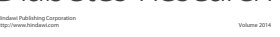

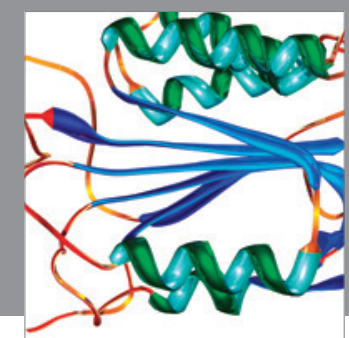

Disease Markers
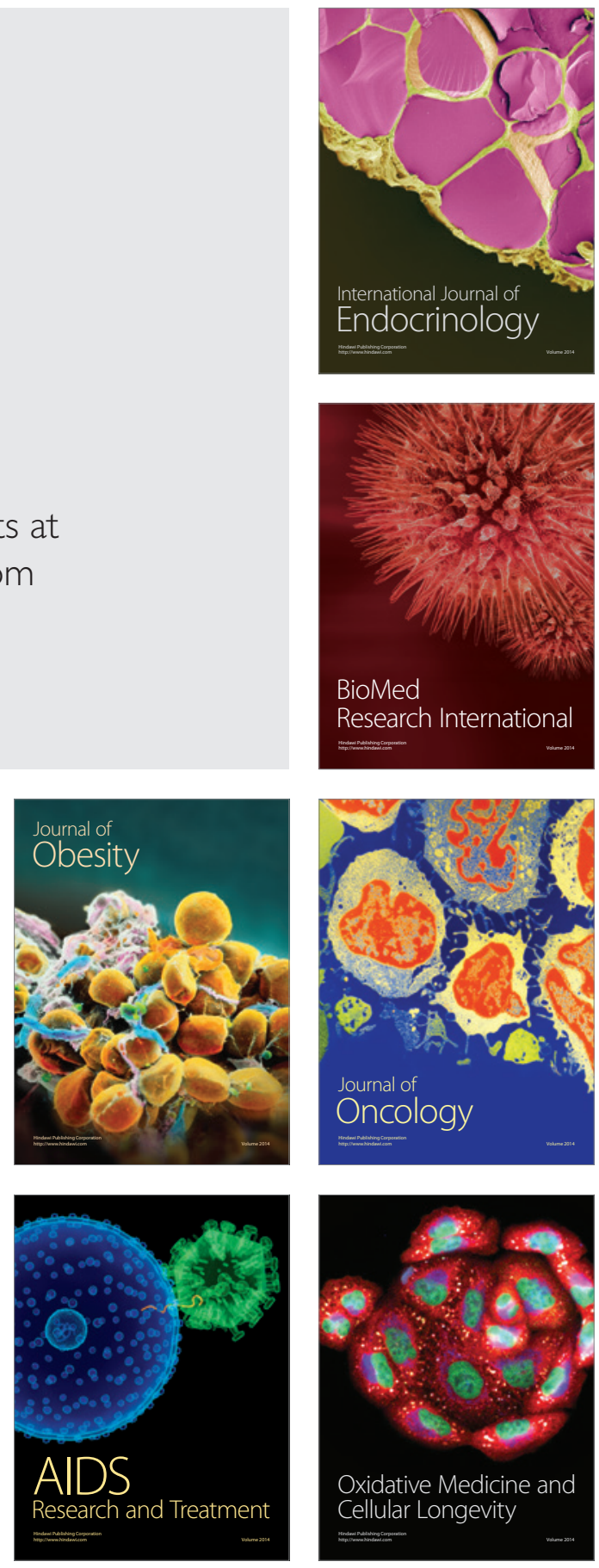